\title{
Knowledge, Barriers, and Motivation Related to Breast and Cervical Cancer Screening Among Women in Bojonegoro, East Java: A Qualitative Study
}

\author{
Afriza Umami1), Sudalhar'), Tegar Wahyu Yudha Pratama', \\ Istiqlal Fitri'2), Andan Firmansyah3)
}

\begin{abstract}
1)Diploma III of Medical Records, School of Health Sciences Muhammadiyah Bojonegoro
2)Bachelor of Hospital Administration, School of Health Sciences Muhammadiyah Bojonegoro

3)Diploma III of Nursing, School of Health Sciences Muhammadiyah Ciamis, West Java
\end{abstract}

\section{ABSTRACT}

Background: Breast and cervical cancer remain a major cause of morbidity and mortality for women in Indonesia. Although this cancer can be detected early, women are still less active in selfdetecting breast and cervical cancer, so both cancers are found at an advanced stage. This study aimed to explore how women's knowledge, barriers, and motivations are related to early detection of breast and cervical cancer.

Subjects and Method: This was a qualitative study, with focus group discussions (FGDs) and interviews with key informants. Discussions and interviews were conducted in the community within Ledok Kulon village, Bojonegoro Regency, East Java, Indonesia. Participants: FGD participants involved 20 women, 10 women underwent FDG about cervical cancer and 10 other women conducted FGD about breast cancer. Three key informants interviewed with health worker and administrator that allow triangulation of responses thereby increasing the validity of the findings. Participants were aged 20 to $\geq 60$ years, with no history of symptoms or previous diagnosis of breast or cervical cancer. The women were interviewed in October-November 2019. The transcribed data were analyzed using content analysis. Results: Participants' knowledge about understanding, risk factors, signs and symptoms of breast and cervical cancer was still lacking. Participants attributed the cause of cervical cancer to the vaginal wound resulting in cervical cancer and signs of symptoms such as heartburn. Whereas for breast cancer participants were not know the signs and symptoms, they only said there was a lump in the breast. Barriers to screening were ashamed to be examined by health workers, afraid of testing procedures, feeling healthy and there were no signs of cancer. Screening motivation were experiencing signs and symptoms of cancer, family history of the disease and awareness of the disease/screening service.

Conclusion: The study participants' knowledge of breast and cervical cancer was still lacking. To improve breast and cervical cancer screening, efforts must focus on reducing identified barriers and increasing motivation.

Keywords: knowledge, barriers, motivation, breast and cervical cancer screening

\section{Correspondence:}

Afriza Umami. Diploma III of Medical Records, School of Health Sciences Muhammadiyah Bojonegoro, Jl. A.Yani No.14, Bojonegoro, Indonesia. Email: afrizaumami20@gmail.com. Mobile: +6282254348041.

\section{Cite this as:}

Umami A, Sudalhar, Pratama TWY, Fitri I, Firmansyah A (2020). Knowledge, Barriers, and Motivation Related to Breast and Cervical Cancer Screening Among Women in Bojonegoro, East Java: A Qualitative Study. J Health Promote Behav. 5(1): 1-10. https://doi.org/10.26911/thejhpb.2020.05.01.01

(c) (i) (-) Journal of Health Promotion and Behavior is licensed under a Creative Commons

Attribution-NonCommercial-ShareAlike 4.0 International License.

\section{BACKGROUND}

The most common cancer affecting women under 60 years globally is breast cancer, followed by cervical cancer. Breast cancer is the leading cause of death among women between the ages of 20 and 59 years (Bray et al., 2018). Cervical cancer globally is the second most common type of cancer among women 
and almost all cases are related to genital infections with Human Papilloma Virus (HPV) (Jradi and Bawazit, 2019).

Nearly $80 \%$ of cases currently occur in low-income countries, where access to cervical cancer screening and prevention services is almost nonexistent. Highly effective vaccines against HPV are now available but costs and accessibility limit their use in less developed countries. Breast and cervical cancer can also be prevented through routine screening coupled with treatment, but this is rarely available in most developing countries (Ndejjo et al., 2017; Wu et al., 2019; Zorogastua et al., 2017).

Cancer is still a serious health problem in Indonesia. The Ministry of Health of the Republic of Indonesia said the prevalence of cancer has increased in the last five years. Currently the prevalence of breast cancer and cervical cancer is the highest type of cancer among women in Indonesia. The highest case was breast cancer at 42.1 per 100,000 population with an average death rate of 17 per 100,000. After that cervical cancer was 23.4 per 100,000 population with an average death of 13.9 per 100,000 population (Basic Health Research, 2018).

Global Cancer Observatory 2018 data from the World Health Organization (WHO) shows the incidence of breast cancer in Indonesia as many as 58,256 cases or $16.7 \%$ of the total 348,809 cancer cases. Cervical cancer is the second most common type of cancer in Indonesia with 32,469 cases or $9.3 \%$ of the total cases (Bray et al., 2018). Efforts to prevent and control both types of cancer are carried out by means of early detection in women aged 30-50 years. The methods used are Clinical Breast Examination (CBE) and visual inspection with acetic acid (VIA) for cervical cancer (Endarti et al., 2018; Farzaneh et al., 2017).

Both of these cancers should be found at an earlier stage, but these cancers are more commonly known at an advanced stage (70\%) which causes high mortality rates. Cervical cancer can be found in the stage before the cancer (precancerous lesions) with the VIA method and Pap smear. If it found at an earlier stage it can reduce mortality and save very high health financing (Ministry of Health data and information center, 2019; Widiasih and Nelson, 2018).

The majority of these deaths can be prevented through HPV vaccination for girls and screening for precancerous lesions for women at risk (Hasahya et al., 2016; Jradi and Bawazir, 2019). Prevention and control interventions against breast cancer have been implemented well in developed countries, so there has been a decrease in cases and detected death rates over the past three decades (Doede et al., 2018; Heena et al., 2019). This is different in developing countries such as Indonesia where there is still low awareness of women to screen for cervical cancer and breast cancer (Endarti et al., 2018; Endriyani et al., 2017; Rio and Suci 2017; Solikhah, 2019). The target of screening for breast and cervical cancer 2018 in Bojonegoro Regency are 203,375 women aged 30-50 years, while those who conduct examinations are only $10 \%$, a total of 19,709 (Bojonegoro Health Office, 2019).

Community level factors such as: knowledge, attitudes and access to screening services can have implications for the successful implementation of screening programs and other public health interventions. Specifically, factors such as feelings of shame, pain received during examinations, fatalism associated with diagnosis, husbands who do not support and increase awareness of breast and cervical cancer screening and available services can help play an important role in increasing screening (Rio and Suci, 2017; Ndejjo et al., 2017; Zorogastua et al., 2017).

Several studies have explored the factors that influence breast cancer and cervical 
cancer screening in Indonesia but most are quantitative and do not have in-depth exploration of these factors to fully inform future interventions. Therefore, the aim of this study is to explore community knowledge, motivations and barriers to breast and cervical cancer screening among women in the Bojonegoro region, Indonesia so as to produce data to inform interventions.

\section{SUBJECTS AND METHOD}

\section{Study design}

This study uses a qualitative design, focus group discussion and interviews with key informants. So that, we can obtain new information, free from the expectations set by authors to learn about the norms and behavior of groups and cultures related to the prevention of breast and cervical cancer among Bojonegoro women.

This approach facilitates the flexible expression of ideas and experiences that might be left behind in the development of structured interview formats, and the collection of iterative data and study question formats allows a thorough exploration from the participant's perspective, which makes it impossible to use quantitative methods (Paramita and Kristiana, 2013; Afiyanti, 2008; Indrizal, 2017).

This study was conducted in the village of Ledok Kulon, Bojonegoro, East Java, from October to November 2019.

\section{Study informants}

The selection of informants in this study uses purposive sampling, which is the technique of determining samples with certain considerations / criteria.

Inclusion criteria:

1. Women aged 20-65 years

2. Cervical and breast cancer have never been detected.
The number of informants in this study amounted to 23 people with the following details:

a. Informants for FGD of 10 people related to breast cancer

b. Informants for FGD of 10 people related to cervical cancer

c. Key informants 3 people

\section{Data analysis}

Data analysis in this study uses content analysis. These themes can be identified, coded inductively (data driven) from raw qualitative data (interview transcripts, biographies, video recordings, etc.) as well as deductively (theory driven) based on theory and the results of previous study. In this study only uses one type of analysis, namely cotent analysis.

The interview was transcribed verbatim as a word document. All transcripts are color coded and labeled according to the information submitted. Similar codes are grouped into themes and sub-themes. Content analysis is applied to identify emerging and recurring themes, and comparisons are made between and within participant groups (Erlingsson and Brysiewicz, 2017; Hsieh and Shannon, 2005).

At this stage, the author lists the ideas that emerge, draws a relationship diagram and identifies key words that are often used by respondents as indicators of important themes. The second stage involves focused coding where the author removes, combines or divides the coding categories identified in the first step. Attention must be taken to repeated ideas and broader themes linking codes. Content analysis enables systematic data coding by organizing information into categories to find patterns that are not detected only by listening to tapes or reading transcripts (Nyumba et al., 2018; Erlingson and Brysiewicz, 2017). 


\section{RESULTS}

\section{Sociodemographic characteristics of participants}

Characteristics of 23 participants, 20 of whom were FGD participants, 3 were key informants, the average age was 48.09 years $(\mathrm{SD} \pm 15.02)$ and most $(11 ; 47.8 \%)$ aged between 51 and 60 years, were married 15 (65.2\%) and most education was 8 high school graduates (34.8\%). Most participants were housewives $(6 ; 26.1 \%)$ and the majority had never been screened for breast and cervical cancer $(20 ; 86.9 \%)$ (Table 1)

Table 1. Socio demographic characteristics of participants

\begin{tabular}{lll}
\hline \multicolumn{1}{c}{ Characteristics } & \multicolumn{1}{c}{$\mathbf{n = 2 3}$} & \multicolumn{1}{c}{ \% } \\
\hline Age (years) & Mean=48.09 \\
& SD \pm 15.02 & \\
20-30 & 5 & 21.7 \\
$31-40$ & 1 & 4.4 \\
$41-50$ & 2 & 8.7 \\
$51-60$ & 11 & 47.8 \\
$\geq 60$ & 4 & 17.4 \\
Marital status & & \\
Married & 15 & 65.2 \\
Not Married & 1 & 4.4 \\
Divorcee & 7 & 30.4 \\
Education level & & \\
Primary School & 4 & 17.4 \\
Junior High School & 6 & 26.1 \\
Senior High School & 8 & 34.8 \\
University & 5 & 21.7 \\
Occupation & & \\
House wife & 6 & 26.1 \\
Employee & 5 & 21.7 \\
Private & 4 & 17.4 \\
Trader & 5 & 21.7 \\
Other (health & 3 & 13.1 \\
worker) & & \\
Screening & & 86.9 \\
Ever & 3 & \\
Never & 20 & \\
\hline
\end{tabular}

\section{Knowledge of breast and cervical can- cer}

This theme explores women's knowledge and awareness about the causes, signs and symptoms, risk factors and screening methods for breast and cervical cancer. In addition, this study explores women's beliefs about the risk of cervical cancer and whether and how this disease can be prevented and treated.

\section{Causes of breast and cervical cancer}

Only a few participants knew about breast and cervical cancer, they got information from their neighbors who had cancer and heard about breast and cervical cancer from health workers in health facilities. However, overall knowledge about breast and cervical cancer is still low, there were some misconceptions among the participants.

Cervical cancer is cancer of the female organ, caused by lack of care of the female organ resulting in irritation, itching, scratching and becoming injured and gradually becoming cancerous (FGD 2, participant 4, 53 years).

Meanwhile, for breast cancer participants also have low knowledge related to understanding and also the cause of breast cancer.

Breast cancer is a lump in the breast and menstrual pain (FGD 1, participant 3, 59 years).

Everyone's level of knowledge is different, it can be communicated when they come to the health service center, if teenagers are educated in the School Health Unit. When married educated about cancer risk factors (health worker "midwife" in the village of Ledok Kulon).

\section{Signs and symptoms}

Participants' knowledge of the signs and symptoms of breast and cervical cancer is very low and they need to be educated more to understand how this disease manifests. People don't even know the symptoms of breast and cervical cancer. Some FGD participants who know the signs and symptoms of breast and cervical cancer have personal experience with this disease or because there are family or neighbors and their friends who have a history of cancer. 
Symptoms of cervical cancer are like heartburn (FGD 2, participant 2, 62 years).

The cause of cervical cancer is due to lack of clean genetalia, not changing underpants (FGD 2, participant 3, 54 years).

Signs and symptoms of breast cancer are breast pain, but I don't know the cause yet (FGD 1, participant 1, 57 years).

\section{Risk Factors}

Participants explained that the risk factor for cancer is death, their understanding of risk factors is still lacking. They assume the risk factor is the impact that will occur if they get cancer. Risk factors have an understanding that every exposure to an individual is related to an increased tendency for disease to occur.

Risk factor of cervical cancer is death (FGD 2, participant 4, 53 years).

Risk factors of breast cancer are due to the use of hormonal contraception (FGD 1, participant 10, 52 years).

The use of hormonal contraception more than 4 years is a risk factor of cancer among women and also the influence of some types of instant food consumed (health worker "midwife").

Hormonal contraception results in the growth of cells outside normal, but inflammation also occurs in the cervix due to hormonal influences (health worker "nurse").

\section{Screening Method}

Among the FGD participants, who had screened cervical cancer with the Pap smear method, while for breast cancer most participants did not know how to detect the cancer.

\section{Early detection}

Early detection of cervical cancer is by pap smear, because I had done this screening about 5 years ago (FGD 2, participant 9, 38 years).

I have never suffered symptoms related to breast cancer so I did not screen for the disease. As such, I don't know what method to use (FGD 1, participant 8, 67 years).

\section{Barriers}

Study participants described that due the lack of knowledge, it was sometimes difficult for them to access screening services because they had no signs and symptoms that led to breast and cervical cancer. Key informants also noted that most women did not take the initiative to access screening without signs and symptoms of the disease.

I didn't do the screening because I was afraid of the inspection (FGD 1, Participant 2, 57 years).

I was embarrassed when I had a pap smear test because it opened a female organ, especially when the doctor was male and was examined by a practical student (FGD 2, participant 3, 54 years).

\section{Barriers to breast cancer screening}

I feel there are no complaints or signs of cancer. So that I don't need to do screening (FGD 1, Participant 9, 62 years).

I don't want screening because I haven't menstruated or I've gone through menopause, I don't think I need screening (FGD 2, Participant 2, 62 years).

Participants found it difficult to be invited to the screening because after hearing stories from their friends who had checked that the examination was very painful during the Pap smear test and had to open the female organs. So that participants reluctant to participate in screening (health worker "midwife")

Previously participants had been educated about breast self-examination and clinical breast examination but only a small number of participants did it (health worker "nurse").

\section{Motivation}

The biggest motivation for screening for cervical cancer among study participants was because they had experienced signs and 
symptoms of the disease that prompted them to visit a health facility for consultation.

I had screened for cervical and breast cancer 5 years ago because at that time there was a free screening in my area. I followed the skiring because I was aware of the signs and symptoms that happened to me, which are often vaginal discharge (FGD 1, Participant 7, 60 years)

My neighbor who died of breast cancer, from there I want to do an early detection of breast and cervical cancer (FGD 1, Participant 4, 61 years).

Some participants have awareness of breast and cervical cancer because they have accessed information mainly through social media and health facilities regarding this disease and understand the importance of screening. In addition, the availability of free screening services in several health facilities.

I want to do a cancer screening in the near future because I realize as a woman, breast and cervical cancer often occurs and early detection must be done immediately (FGD 2, Participants 7, 26 years).

Health workers in the village of Ledok Kulon said that there was a free cancer screening test for women at the community health center.

Every Saturday there is a free IVA examination at the "Wisma Indah" community health center (midwife and nurse from Ledok Kulon).

\section{DISCUSSION}

This study explores women's knowledge about motivations and barriers to cervical cancer screening in Bojonegoro, namely in the village of Ledok Kulon. The results of the study explained that, knowledge about the causes of cervical cancer, signs and symptoms, screening methods and prevention are still lacking. This is consistent with findings from a study by Endarti (2018) in Yogyakarta. Common misconceptions about cervical cancer include understanding, signs and symptoms such as stomach pain such as gastritis and also cancer that occurs in the vagina. This is very different from the existing theoretical concept that cervical cancer is caused by the HPV virus that attacks the female cervix (Rerucha et al., 2018; Cohen et al., 2019) while breast cancer is cancer that grows in the breast (Henry et al., 2019).

Awareness of some of the risk factors for breast and cervical cancer is still very low because participants do not know about any of these cancer risk factors. They assume that the risk factor is the occurrence of a death or the risk that they will get when suffering from cancer. risk perception is an important factor in promoting preventive health behaviors and has been a determinant of breast and cervical cancer screening in previous studies (Modibbo et al., 2015; Mamdouh et al., 2014; Ndejjo et al., 2017; Wu et al., 2019; Zorogastua et al., 2017). A study by Umami et al. (2018), stated that the risk of cervical cancer is poor genital hygiene, and is also caused by biopsychosocial factors such as parity, economic status, and stress levels.

Although among the FGD participants, only 3 out of 20 have been screened for breast and cervical cancer, only a small number of participants showed an interest in accessing services regularly. Cervical cancer screening has also been documented by previous studies in Yogyakarta (Endarti et al., 2018). The motivation for screening breast and cervical cancer among study participants was: experiencing signs and symptoms of cancer, families with a history of cancer and being aware of cancer and screening services, this is similar to those reported by previous studies (Zorogastua et al., 2017).

The belief among study participants that screening must be accessed after experiencing signs and symptoms of cancer is a negative perception that must be changed because this will result in the failure of the 
screening program. The government must further strengthen the need to raise awareness about breast and cervical cancer among women. In fact, preference for screening is asymptomatic women, educational campaigns should encourage women aged between 30 and 49 years to screen for cervical cancer at least once in their lifetime as recommended by WHO (Curry, 2018).

The availability of services is not enough to facilitate screening, steps must be taken to publicize the service, to increase the absorption of screening including through the use of mass media such as internet and television. Community motivation and mobilization for cancer programs can also be contributed by public health workers, in supporting the health system, especially in developping countries. Indeed, public health workers have made a significant contribution to the screening of breast and cervical cancers as well as previous prevention efforts (Ndejjo et al., 2018).

In this study, barriers to breast and cervical cancer screening reported were: lack of knowledge about cancer and screening; health system challenges; fear when being examined, worry about the results and consequences of the test; shame when will be checked, feel no complaints. These barriers are similar to those documented by previous studies (Ndejjo et al., 2018; Wu et al., 2019; Zorogastua et al., 2017). To facilitate absorption of breast and cervical cancer screening, motivation must be made to increase awareness about the disease and the importance of screening. The importance of increasing access to cancer screening services in the community to overcome health system challenges such as distance to health facilities and transportation costs of this study is in line with the results of study conducted by Modibbo (2015) and Mamdouh (2014) that barriers to screening are due to lack of knowledge and awareness of signs of cancer, fear and shame of health workers who carry out screening checks because of gender differences.

This study has strengths and limitations. First, ask for views from women using FGDs and Key Informants that allow for various responses and enable triangulation of findings thereby increasing the validity of study. Second, data collection is done in a natural environment that provides a conducive environment for women to openly express themselves and share experiences. However, the FGD environment can influence participants to give answers that they think are more socially acceptable. Also, during the FGD, sometimes there were participants who were outspoken in answering questions so that they could be minimized by having experienced moderators who could master the forum so that all participants were involved in the discussion. Finally, the study was conducted in the city of Bojonegoro and the results cannot be generalized to all countries, this study reports important information that can play a role in the design of breast and cervical cancer programs and services in the future.

The knowledge of study participants about breast and cervical cancer is still low, resulting in low awareness of screening and urgent need to prioritize sensitivity and provide adequate information about cancer among women. Efforts to increase screening for breast and cervical cancer must be carried out by focusing on reducing the identified barriers and increasing motivation through measures such as raising awareness about the disease, strengthening the capacity of the health system and using female health workers to screen.

\section{AUTHOR CONTRIBUTION}

Afriza Umami conceived, designed the study, and drafted the manuscript. Sudalhar, Tegar Wahyu Yudha Pratama, and Istiqlal Fitri collected the data, arranged questionnaire, 
interpreted the results of data analysis. Andan Firmansyah revised the manuscript, provided valuable intellectual content. All authors commented on and approved the final manuscript.

\section{CONFLICT OF INTEREST}

The authors disclosed receipt of the following financial support for the stduy, authorship, and/or publication of this article. Support for the study and authorship of this article was funded by STIKES Muhammadiyah Bojonegoro Research and Community Service Institute.

\section{FUNDING AND SPONSORSHIP}

The author would like to thank the STIKES Muhammadiyah Bojonegoro, the elderly assistance office in the village of Ledok Kulon, which has supported both financially and full support for the completion of this study. Thank you also to the study assistants for the support they provided during the data collection and to the study participants for their time and contribution to this study.

\section{ACKNOWLEDGEMIENT}

The author would like to thank the STIKES Muhammadiyah Bojonegoro, the elderly assistance office in the village of Ledok Kulon, which has supported both financially and full support for the completion of this study. Thank you also to the study assistants for the support they provided during the data collection and to the study participants for their time and contribution to this study.

\section{REFERENCE}

Afiyanti Y (2008). Focus group discussion as a qualitative research data collection method. Indonesian Nursing Journal, 12 (1): 58-62

Basic Health Research (Riskesdas) (2018). Indonesian Ministry of Health Research and Development Agency 2018. http://www.depkes.go.id/resources- /download/infoterkini/materi_rakorpop_2018/Hasil\%2oRiskesdas\%202018.pdf. Accessed August 2018.

Bojonegoro Health Office (2019). Report on the prevention and eradication of noncommunicable diseases in the $\mathrm{P} 2 \mathrm{P}$ field 2018.

Bray F, Ferlay J, Soerjomataram I, Siegel RL, Torre LA, Jemal A (2018). Global cancer statistics 2018: Globocan estimates of incidence and mortality worldwide for 36 cancers in 185 countries. Ca Cancer J Clin, 68: 394-424.

Cohen PA, Jhingran A, Oaknin A, Denny L (2019). Cervical cancer. The Lancet, 393(10167): 169-182. doi: 10.1016/s0140-6736(18)32470-x

Curry SJ (2018). Screening for Cervical Cancer US Preventive Services Task Force Recommendation Statement. JAMA, 320(7): 674-686. Doi:10.1001/jama.2018.10897

Doede AL, Mitchell EM, Wilson D, Panagides R, Oriá MOB (2018). Knowledge, beliefs, and attitudes about breast cancer screening in Latin America and the Caribbean: An in-depth narrative review. Journal of Global Oncology.

Endarti D, Satibi, Kristina SA, Farida MA, Rahmawanti Y, Andriani T (2018). Knowledge, perception, and acceptance of HPV vaccination and screening for cervical cancer among Women in Yogyakarta Province, Indonesia. Asian Pac J Cancer Prev, 19(4): 1105-1111. doi: 10.22034/APJCP.2018.19.4.1105.

Endriyani A, Dasuki D, Mawarti R (2017). Analysis of cervical cancer screening program in Sleman DIY: Qualitative Study. Journal of Midwifery and Nursing, 13(2): 95-103

Erlingsson C, Brysiewicz P (2017). A hand-on guide to doing connect analysis. African Journal of Emergency Medicine, 7: 9399. 
Farzaneh E, Heydari H, Shekarchi AA, Kamran A (2017). Breast and cervical cancer-screening uptake among females in Ardabil, Northwest Iran: a community-based study. Onco Targets and Therapy, 10: 985-992.

Global Cancer Observatory (2018). Globocan - Indonesia. https://gco.iarc.fr/today/data/factsheets/populations/360indonesia-fact-sheets.pdf

Hasahya OT, Berggren V, Sematimba D, Nabirye RC, Kumakech E (2016). Beliefs, perceptions and health-seeking behaviours in relation to cervical cancer: a qualitative study among women in Uganda following completion of an HPV vaccination campaign. Glob Health Action, 9:29336. Doi.org/10.3402/gha.v9.29336

Heena H, Durrani S, Riaz M, AlFayyad I, Tabasim R, Parvez G, Abu-Shaheen A (2019). Knowledge, attitudes, and practices related to breast cancer screening among female health care professionals: a cross sectional study, BMC Women's Health 19:122. https://doi.org/10.1186/s12905-019-0819-X

Henry NL, Shah PD, Haider I, Freer PE, Jagsi R, Sabel MS (2019). Chapter 88: Cancer of the Breast. In: Niederhuber JE, Armitage JO, Doroshow JH, Kastan MB, Tepper JE, eds. Abeloff's Clinical Oncology. 6th ed. Philadelphia, Pa: Elsevier.

Hsieh HF, Shannon SE (2005). Three approaches to qualitative content analysis. Qualitative Health Research, 15 (9): 1277-1288. doi: 10.1177/1049732305276687 .

Indrizal, E (2017). Focus Group Discussion (FGD) (Principles and Steps for Field Implementation). Journal of Anthropology: Socio-Cultural Issues, 16(1): 7582.
Jradi H, Bawazir A (2019). Knowledge, attitudes, and practices among Saudi women regarding cervical cancer, $\mathrm{Hu}-$ man papillomavirus (HPV) and corresponding vaccine. Vaccine, 37: 530-537.

Mamdouh HM, Mansy H, Kharboush IF, Ismail HM, Tawfik MM, Baky MA, Sharkawy GE (2014). Barriers to breast cancer screening among a sample of Egyptian females. Journal of Family and Community Medicine, 21 (2): 119124.

Ministry of Health data and information center (2019). Indonesia Health Profile 2018. Ministry of Health of the Republic of Indonesia; Jakarta. ISBN 978-602-656-446-4

Modibbo FI, Dareng E, Bamisaye P, Elima Jedy-Modibbo FI, Dareng E, Bamisaye $\mathrm{P}$, Jedy-Agba E, Adewole A, Oyeneyin L, Olaniyan O, Adebamowo C (2015). Qualitative study of barriers to cervical cancer screening among Nigerian women. BMJ Open, 6: eoo8533. doi: 10.1136/bmjopen-2015008533

Ndejjo R, Mukama T, Kiguli J, Musoke D (2017). Knowledge, facilitators and barriers to cervical cancer screening among women in Uganda: a qualitative study. BMJ Open, 7:e016282. doi: 10.1136/ bmjopen-2017-016282

Nyumba TO, Wilson K, Derrick CJ, Mukherjee $N$ (2018). The use of focus group discussion methodology: Insights from two decades of application in conservation. Methods Ecol Evol, 9: 20-32.

Paramita A, Kristiana L (2013). Focus group discussion technique in qualitative research. Health System Research Bulletin. 16(2): 117-127.

Rerucha CM, Caro RJ, Wheeler VL (2018). Cervical Cancer Screening. American Family Physician, 97 (7): 441-448C.

Rio S \& Suci EST (2017). Perceptions about cervical cancer and its prevention ef- 
forts in women who have families with a history of cancer. Journal of Reproductive Health, 4 (3): 159-169

Solikhah S (2019). Breast Cancer Screening among Indonesian Women. Jurnal Media Kesehatan Masyarakat Indonesia, 15 (1). doi: http://dx.doi.org/10.30597/mkmi.v15i1.5501

Umami A, Rahardjo SS, Murti B (2018). Path Analysis on the Biopsychosocial Determinants and Genital Hygiene on Cervical Cancer at Dr. Moewardi Hospital, Surakarta, Central Java. Journal of Epidemiology and Public Health, 3(2): 277-291. https://doi.org/10.26911/jepublichealth.2018.03.02.07

Widiasih R, Nelson K (2018). Muslim Husbands' Roles in Women's Health and
Cancer: The Perspectives of Muslim Women in Indonesia. Asian Pac J Cancer Prev, 19 (6): 1703-1709. doi: 10.22034/APJCP.2018.19.6.1703

Wu Z, Liu Y, Li X, Song B, Ni C, Lin F (2019). Factors associated with breast cancer screening participation among women in mainland China: a systematic review. BMJ Open, 9: e028705. doi: 10.1136/ bmjopen-2018-028705

Zorogastua K, Sriphanlop P, Reich A, Aly S, Cisse A and Jandor L (2017). Breast and Cervical Cancer Screening among US and nonUS Born African American Muslim Women in New York City. AIMS Public Health, 4(1): 78-93. Doi: 10.3934/publichealth.2017.1.78 